\title{
Effects of feeding starch sugar by-products on in situ rumen disappearance rate, growth performance, and carcass characteristics of late finishing Hanwoo steers
}

\author{
Yongjun Choi ${ }^{1}$, Geetae Park ${ }^{1}$, Hyokon Kang ${ }^{1}$, Jiyeon Ahn ${ }^{1}$, Eunchae Lee ${ }^{1}$, \\ Youngjun $\mathrm{Na}^{1,2}$, and Sangrak Lee ${ }^{1, *}$
}

\begin{abstract}
* Corresponding Author: Sangrak Lee Tel: +82-2-450-3696, Fax: +82-2-455-1044, E-mail: leesr@konkuk.ac.kr
\end{abstract}

${ }^{1}$ Department of Animal Science and Technology, Konkuk University, Seoul 05029, Korea

2 Animal Data Laboratory, Antller Inc., Seoul 05029, Korea

ORCID

Yongjun Choi

https://orcid.org/0000-0002-5759-4108 Geetae Park

https://orcid.org/0000-0002-0596-6504 Hyokon Kang

https://orcid.org/0000-0001-7226-875X Jiyeon Ahn

https://orcid.org/0000-0002-5957-3394

Eunchae Lee

https://orcid.org/0000-0003-0143-4022

Youngjun $\mathrm{Na}$

https://orcid.org/0000-0002-4643-0191

Sangrak Lee

https://orcid.org/0000-0002-8905-0770

Submitted Mar 18, 2021; Revised Apr 16, 2021; Accepted Jul 4, 2021
Objective: The aim of this study was to determine the effects of feeding starch sugar byproducts (SSBs) on in situ disappearance rate, performance, and carcass characteristics of Hanwoo steers in the late finishing stage.

Methods: To determine the in situ disappearance rate, nylon bags filled with $5 \mathrm{~g}$ of SSB were inserted into the ventral sac of two cannulated Holsteins cows and incubated for 0, 2, 4, 8, 16,24 , and $48 \mathrm{~h}$. A total of 30 Hanwoo steers were fed the experimental diets, which were basal diet (control) and 7\% SSB on an as-fed basis (4.35\% dry matter [DM]), formulated according to requirements of the Korean Feeding Standard for Hanwoo. The experiment was conducted over 80 days using a completely randomized block design.

Results: Soluble fraction $a$ of DM and organic matter (OM) was $44.20 \%$ and $64.60 \%$ DM, fraction $b$ was $23.00 \%$ and $19.40 \% \mathrm{DM}$, and $c$ values (the rate of degradation of fraction $b$ ) were 0.04 and $0.04 / \mathrm{h}$, respectively. The effective degradability of DM at rumen solid outflow rates of $0.02,0.05$, and $0.08 / \mathrm{h}$ was $59.83,54.75$, and 52.16 , respectively, and for OM was $77.78,73.52$, and 71.34 , respectively. Initial and final body weight, average daily gain, DM intake, and gain:feed did not differ significantly between control and SSB groups during the entire experimental period. Carcass traits of Hanwoo steers with SSB supplementation were not significantly different between treatments except for dressing percentage, which was greater with SSB treatment. The content of saturated fatty acid (SFA) was greater and that of unsaturated fatty acids (UFA) was lower in the SSB group than in the control group. The ratio of UFA to SFA was significantly lower in the SSB group than in the control group. Conclusion: A total mixed ration containing less than 4.0\% DM of SSBs can be used in Hanwoo steers without a decrease in productivity and carcass traits.

Keywords: Starch Sugar By-product; In situ Disappearance Rate; Performance; Carcass Characteristics; Hanwoo Steers

\section{INTRODUCTION}

In the modern livestock industry, grains and pulses are used as common feed ingredients for high producing animals; however, there is competition for these ingredients with humans. A discarded agricultural by-product is a secondary product generated during the processing of grains, vegetables, or fruits [1]. Most by-products are human-inedible, and they can be utilized as an animal feed ingredient because they contain adequate organic materials for digestion. The starch sugar by-product (SSB) is produced by the following process: i) liquid starch passes through the filter to absorb useful saccharides into the center and ii) residue remains on the surface, which is separated using a knife [2] (Figure 1). The extracted sugar through the filter may contain starch in the residue and this could affect 


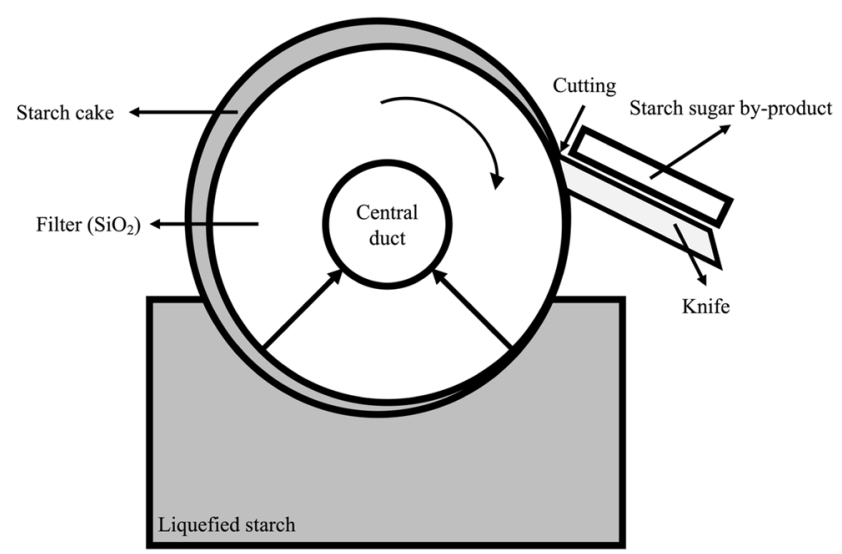

Figure 1. Starch sugar by-product (SSB) producing process. The target saccharides produced by fermentation are passed through the filter and remain stuck to the surface of the filter. The residues on the filter are peeled using a knife to maintain maximum absorption efficiency.

the rumen fermentation in case of use as a feed ingredient. Generally, because the filter is made of silica $\left(\mathrm{SiO}_{2}\right)$, SSB indispensably contains not only starch sugar residue but also some of the silica which generated through the filter-cutting process. There was reported that the filter cake of sugarcane showed ash $10 \%$ to $14 \%$ dry matter (DM) and silica $4 \%$ to $10 \% \mathrm{DM}$ of ash [3]. Although silica is an essential material for bone formation in young animals [4], a high level of silica in animal feed has a negative effect on the digestibility of cell wall components [5] and can induce formation of urinary tract stones (siliceous urinary calculi) [6]. Although a watersoluble form of silica in feed can have a negative effect on livestock, silica generally has a very low solubility ( 7 to $8 \mathrm{~g}$ per $50 \mathrm{~kg}$ BW in sheep) near rumen temperature [7]. However, since silica in SSB is not in a water-soluble form, the negative effect is small in the ruminant.

The market for grain-originated refined starches (glucose, oligosaccharide, or syrup) is increasing constantly, causing an increase in SSBs. Most starch and sugar are manufactured by six companies in South Korea and the SSB produced is about 1,000 tons per month in South Korea [8]. Generally, most SSB is immediately collected by waste treatment companies as soon as it is produced. In waste treatment companies, SSB has been sold as a feed ingredient when there is demand and otherwise discarded. These SSBs contain sufficient nutritive value to utilize as an animal feed ingredient [9]. However, some aspects need to be evaluated to eliminate potential antinutritional factors such as lipid and ash contents to affect the digestibility and toxicity in the ruminant. Currently, research on SSB effects on the ruminant is very scarce.

Therefore, the objectives of the present study were to evaluate the effect of SSBs on i) rumen in situ disappearance rate and ii) growth performance and carcass characteristics of late finishing Hanwoo steers.

\section{MATERIALS AND METHODS}

\author{
Animal care \\ All research protocols were approved by the Konkuk Uni- \\ versity Animal Care and Use Committee (approval number: \\ KU18094).
}

\section{Starch sugar by-products}

The SSB used in the experiment is the residue left after extracting starch sugar using corn as raw material, and it was obtained from the starch sugar factory of Sajo Donga Won Industry (Dangjin, Korea). The collected SSB sample was stored at $-20^{\circ} \mathrm{C}$ until analysis and experimentation. The chemical composition of the SSBs is shown in Table 1 and Supplementary Table S1.

\section{In situ disappearance rate}

The experiment was performed at an experimental farm at Chungju-si, Chungchungbuk-do, South Korea (latitude $37.07^{\circ}$ and longitude $127.86^{\circ}$ ). Two ruminally cannulated Holstein Friesian cows were used. They were fed commercially prepared pellet feed (DM, 90.6\%; crude protein [CP], 21.7\% DM; neutral detergent fiber [NDF], 35.8\% DM; acid detergent fiber $[\mathrm{ADF}], 14.1 \% \mathrm{DM}$; ether extract [EE], 5.2\% $\mathrm{DM}$; ash, 7.4\% DM) and tall fescue (DM, 91.5\%; CP, 7.7\% DM; NDF, 68.7\% DM; ADF, 40.5\% DM; EE, 0.9\% DM; ash, $7.9 \% \mathrm{DM}$ ) at a ratio of $7: 3$, respectively. The experimental diet was fed at $2 \%$ of body weight (BW) during the experimental periods and water and mineral blocks were provided ad libitum.

The dried SSB samples were milled to pass through a 1 mm screen (Wiley Mill; Thomas Scientific, Swedesboro, NJ, USA). Nylon bags $(5 \times 10 \mathrm{~cm}, 45 \mu \mathrm{m}$ pore size; R510, ANKOM Inc., Macedon, NY, USA), in triplicate, filled with $5 \mathrm{~g}$ of SSB were inserted into the rumen ventral sac of two cannulated Holstein cows and incubated for $0,2,4,8,16,24,48$, and 72 $\mathrm{h}$ according to the NRC guideline [6]. After incubation, the

Table 1. Chemical composition of rice bran and starch sugar by-product $(n=3)$

\begin{tabular}{lcc}
\hline Items & Rice bran & SSB \\
\hline $\mathrm{DM}(\%)$ & $88.19 \pm 0.3$ & $62.15 \pm 0.8$ \\
$\mathrm{CP}(\% \mathrm{DM})$ & $15.41 \pm 0.8$ & $15.29 \pm 0.4$ \\
$\mathrm{EE}(\% \mathrm{DM})$ & $19.22 \pm 0.8$ & $24.68 \pm 0.2$ \\
$\mathrm{Ash}(\% \mathrm{DM})$ & $9.17 \pm 0.9$ & $12.96 \pm 0.5$ \\
$\mathrm{NDF}(\% \mathrm{DM})$ & $28.43 \pm 3.1$ & $33.36 \pm 0.2$ \\
$\mathrm{ADF}(\% \mathrm{DM})$ & $12.17 \pm 0.9$ & $5.71 \pm 0.1$ \\
$\mathrm{ADL}(\% \mathrm{DM})$ & $\mathrm{NA}$ & $2.31 \pm 0.1$ \\
$\mathrm{NFC}(\% \mathrm{DM})$ & $27.76 \pm 4.2$ & $13.71 \pm 0.8$ \\
$\mathrm{SiO}_{2}(\% \mathrm{DM})$ & $\mathrm{NA}$ & $12.14 \pm 0.12$ \\
\hline
\end{tabular}

SSB, starch sugar by-product; DM, dry matter; CP, crude protein; EE, ether extract; NDF, neutral detergent fiber; ADF, acid detergent fiber; ADL, acid detergent lignin; NFC, non-fiber carbohydrate; NA, not analyzed. 
nylon bags were removed from the rumen, washed under running tap water for $2 \mathrm{~min}$ and then washed in the cold rinse cycle $\left(10 \mathrm{~min}\right.$ ) by hand, dried at $60^{\circ} \mathrm{C}$ for $48 \mathrm{~h}$, and then weighed for the analysis of DM and CP. Degradation was calculated using the formula proposed by Ørskov and McDonald [10]:

$$
\mathrm{P}=a+b\left(1-\mathrm{e}^{-\mathrm{ct}}\right)
$$

where $\mathrm{P}$ is the actual degradation after time $\mathrm{t} ; \boldsymbol{a}$ is the intercept of the degradation curve at time zero; $b$ is the potential degradability of the component of the protein which will, in time, be degraded; $c$ is the rate constant for the degradation of $b$; and $t$ is time. Regression analysis was performed using SAS PROC REG (Version 9.4, SAS Institute Inc., Cary, NC, USA) for estimation of the fraction $b$.

The effective degradability (ED) of DM and CP was calculated using the following equation:

$$
\mathrm{ED}=a+(b \times c) /(c+k)
$$

where $k$ is the estimated rate of outflow from the rumen and $a, b$, and $c$ are the same parameters as described above. The ED was estimated as ED2, ED5, and ED8, assuming rumen solid outflow rates of $0.02,0.05$, and $0.08 / \mathrm{h}$, which are representative of low, medium, and high feed intake, respectively [11].

\section{Animal and experimental design}

A total of 30 Hanwoo steers $(28.2 \pm 0.26$ months old, $806.2 \pm$ $28.2 \mathrm{~kg} \mathrm{BW}$ ) were used for the experiment. Animals were allocated according to ages and initial BW and then allotted to six sawdust-bedded pens (five heads/pen) and randomly fed the experimental diets (Table 2) during the entire experimental periods. The treatments were basal diet (control) and $7.0 \%$ of SSB on an as-fed basis ( $4.35 \%$ of DM), with the diet formulated according to the requirements of the Korean Feeding Standard for Hanwoo [12] (Table 2). The experiment was conducted using a randomized complete block design for 80 days. Experimental diets were fed once a day at 0800 $\mathrm{h}$ ad libitum in the form of total mixed ration with $5 \%$ refusals. Water and mineral blocks were also available ad libitum. The offered diets and refusals were measured daily for the calculation of DM intake (DMI), and BW was measured at day 0 and 80 (at $858 \pm 7.8$ days old, respectively) from the start of the experiment. The DMI and BW were used to calculate average daily gain (ADG) and gain:feed. Experimental diets were sampled monthly and stored at $-20^{\circ} \mathrm{C}$ for subsequent chemical analysis. After the end of the study, animals were slaughtered in the commercial slaughterhouse (Meat Processing Facility, Gyoungsangbuk-do, Korea) using a pistol equipped with an air compressor.
Table 2. Ingredients and chemical composition of the total mixed rations

\begin{tabular}{lcc}
\hline Items & Control & SSB \\
\hline Ingredient (as-fed basis, \%) & & \\
Corn & 25.0 & 26.7 \\
Commercial feed ${ }^{1)}$, pelleted & 10.0 & 10.0 \\
Commercial feed ${ }^{2}$, pelleted & 15.0 & 15.0 \\
Rice bran & 7.0 & - \\
SSB & - & 7.0 \\
Molasses & 5.0 & 5.0 \\
Soybean meal & 3.0 & 3.3 \\
Soybean curd cake & 10.0 & 10.0 \\
Straw & 8.0 & 8.0 \\
Water & 17.0 & 15.0 \\
Total & 100.0 & 100.0 \\
Chemical composition & & \\
DM (\%) & 65.31 & 65.21 \\
CP (\% DM) & 13.05 & 13.10 \\
EE (\% DM) & 4.75 & 4.94 \\
CF (\% DM) & 9.45 & 9.00 \\
Ash (\% DM) & 5.81 & 6.30 \\
NDF (\% DM) & 25.10 & 23.43 \\
ADF (\% DM) & 13.07 & 12.20 \\
\hline
\end{tabular}

SSB, starch sugar by-product; DM, dry matter; CP, crude protein; EE, ether extract; $C F$, crude fiber; NDF, neutral detergent fiber; ADF, acid detergent fiber; TDN, total digestible nutrients.

1) DM, 86.96\%; TDN, 70.78\%; CP, 10.5\%; CF, 6.6\%; NDF, 23.6\%; ADF, $11.93 \%$; Ash, 7.09\%; Ca, 0.94\%; P, 0.36\%.

2) $\mathrm{DM}, 88.08 \%$; TDN, 70.15\%; CP, 20.1\%; CF, 7.18\%; NDF, 28.79\%; ADF, 13.28\%; Ash, 8.36\%; Ca, 1.03\%; P, 0.51\%.

\section{Chemical analysis}

All samples were dried in a drying oven (HB-503-LF; Hanbaek Scientific Technology, Bucheon, Korea) at $60^{\circ} \mathrm{C}$ for 48 h. DM (method No. 937.01), CP (method No. 990.03), EE (method No. 920.39), ash, and silica (method No. 920.08) were analyzed according to the methods of AOAC International [13]. The NDF (method No. 2002.04) and ADF (method No. 973.18) were analyzed using the ANKOM Fiber Analyzer (A200, ANKOM Inc., USA) according to method proposed by Mertens [14] and Van Soest et al [15], respectively. Acid detergent lignin was determined using a filter bag (F57, Ankom Inc., USA) and beaker according to method described by Möller [16]. The non-fiber carbohydrate content was calculated by subtracting the sum of $\mathrm{CP}, \mathrm{EE}$, ash, and NDF from 100.

\section{Carcass traits}

To evaluate the carcass traits, all animals were transported to a commercial slaughterhouse (Meat Processing Facility, Korea) and slaughtered after $24 \mathrm{~h}$ of rest. At $24 \mathrm{~h}$ postmortem, carcass traits, including back fat thickness, dressing percentage, longissimus muscle (LM) area, carcass weight, marbling score, and quality grade were determined following the guidelines of the Animal Products Grading Service, Korea [17]. 
Approximately $300 \mathrm{~g}$ of LM tissue samples were collected from all steers and stored with vacuum packing at $-80^{\circ} \mathrm{C}$ until subsequent fatty acid (FA) analyses.

\section{Fatty acid composition analysis}

For FA analysis, the lipid material of the SSB samples was extracted using a methanol:chloroform $(1: 2, \mathrm{v} / \mathrm{v})$ solvent [18] and then methylated [19]. After pretreatment, the supernatant was injected into a gas chromatograph (Agilent 6890, NY, USA) equipped with a flame ionization detector and a capillary column ( $30 \mathrm{~m} \times 0.25 \mathrm{~mm} \times 0.25 \mu \mathrm{m}$; No. 122-3232, Agilent, USA) operated with the oven at $50^{\circ} \mathrm{C}$ [20]. The inlet and detector temperatures were $180^{\circ} \mathrm{C}$ and $250^{\circ} \mathrm{C}$, respectively. Helium was used as the carrier gas.

\section{Statistical analysis}

Data were analyzed using a MIXED procedure of the SAS 9.4 software (SAS Inst. Inc., Cary, NC, USA) [21] as a completely randomized block design. The model was:

$$
\mathrm{Y}_{\mathrm{i}(\mathrm{t})}=\mu+\mathrm{B}_{\mathrm{i}}+\mathrm{T}_{\mathrm{j}}+\mathrm{E}_{\mathrm{ij}(\mathrm{t})} \text {, }
$$

where $\mu$ is the average value, $B_{i}$ is block, $T_{j}$ is treatment value, and $\mathrm{E}_{\mathrm{ij}(\mathrm{t})}$ is the error value. The fixed effect was SSB, and random effect was initial BW of each pen. Statistical significance was compared between control and SSB treatment groups using the T-test option. Least square means between treatments were assessed using a pairwise comparison method. Statistical difference and tendency were accepted at a p-value less than 0.05 and 0.10 , respectively. All means are presented as least square means.

\section{RESULTS AND DISCUSSION}

Dry matter and organic matter $(\mathrm{OM})$ degradation parameters, and the ED values of the SSB are presented in Table 3. Soluble fraction $a$ of DM and OM was $44.2 \%$ and $64.6 \% \mathrm{DM}$, fraction $b$ of DM and OM was $23.00 \%$ and $19.40 \% \mathrm{DM}$, and constant $c$ and $\mathrm{OM}$ was 0.04 and 0.04 , respectively. The ED2, ED5, and ED8 of DM were 59.83, 54.75, and 52.16, respectively and those of OM were $77.78,73.52$, and 71.34 , respectively. The SSBs are separated from the mixture of starch sugar liquid and filter using physical methods such as a blade (Figure 1) and this process might influence the physical and chemical composition of the SSBs. In a previous experiment, the SSB collected from multiple time-points showed a high variation among physical and chemical characteristics [22]. This high variation in the SSB is one of the factors that could make it difficult to use as a feed ingredient. The DM, CP, EE, ash, $\mathrm{NDF}$, and ADF content in the SSB used in the previous experiment was $61.4 \%, 14.4 \%, 23.26 \%, 32.6 \%, 35.7 \%$, and $31.3 \%$ of DM, respectively [22]. As a high ash content, containing
Table 3. Changes in in situ disappearance rate of dry and organic matter of the starch sugar by-product in the rumen

\begin{tabular}{lcc}
\hline \multirow{2}{*}{ Items } & \multicolumn{2}{c}{ In situ disappearance rate of SSB (\% DM) } \\
\cline { 2 - 3 } & DM & OM \\
\hline Incubation time $(h)$ & & \\
0 & 45.83 & 60.48 \\
2 & 58.39 & 67.35 \\
4 & 59.20 & 68.00 \\
8 & 64.14 & 72.64 \\
16 & 65.10 & 73.65 \\
24 & 68.27 & 76.74 \\
48 & 67.20 & 75.41 \\
72 & 77.21 & 83.96 \\
Degradation parameter ${ }^{1)}$ & & \\
a (\% DM) & 44.20 & 64.60 \\
b (\% DM) & 23.00 & 19.40 \\
C ( ${ }^{-1}$ ) & 0.04 & 0.04 \\
ED $^{2)}(\%$ DM) & & \\
ED 2 & 59.83 & 77.78 \\
ED 5 & 54.75 & 73.52 \\
ED 8 & 52.16 & 71.34 \\
\hline
\end{tabular}

SSB, starch sugar by-product; DM, dry matter; OM, organic matter; ED, effective degradability.

1) $a$, the water-soluble fraction which is rapidly washed out of bags and assumed to be completely degradable; $b$, the slowly degradable fraction; $c$, the rate of degradation of fraction " $b$ "

2) Fractional rate of passage out of the rumen, wherein ED2, ED5, and ED8 are assumed as $0.02,0.05$, and $0.08 / h$, respectively.

silica, could have negative effects when fed to ruminants [6,7], a low percentage of the SSB ( $3 \%$ of DM) was fed to dairy cows in the previous study [22]. However, the SSB used in this study showed lower ash content (13.0\% of DM) than that in the previous study (32.6\% of DM; [22]), approximately half on an as-dry basis. Therefore, it was considered that a larger amount could be used, and approximately 4.35\% DM of SSB was fed to Hanwoo steers in this experiment. Furthermore, the silica content of SSB used in this experiment showed $12.14 \%$ of DM (Table 1), feeding $4.35 \%$ of DM SSB to a ruminant is equivalent to feeding $0.53 \% \mathrm{DM}$ silica, and it is considered that could be fed without any negative effects. The SSB used in this experiment showed a lower range of ED values than obtained in the previous study $(63.3 \%$ vs $70.5 \%$ [22]). Furthermore, the ED value of the SSB in this experiment was lower than the commonly observed $\mathrm{ED}$ value for corn grain and soybean $[23,24]$. However, it is noteworthy that the degradation parameter constant $c$ of the SSB in this study (constant c, 0.04) was lower than that of the SSB in the previous study (constant c, 0.23) [22]. Considering degradation parameters, fraction $b$ indicates the potential degradability of the component of DM or $\mathrm{CP}$ which will, in time, degrade and constant $c$ value indicates the rate constant for the degradation of fraction $b[10]$. It has been reported that as constant $\mathrm{c}$ value becomes closer to zero, the digestibility of feed ingredients in the rumen increases $[25,26]$. Considering the result 
Table 4. Effects of the dietary starch sugar by-product as a total mixed ration ingredient on body weight, average daily gain, dry matter intake, and gain:feed of Hanwoo steers

\begin{tabular}{lcccc}
\hline Items & Control & SSB & SEM & p-value \\
\hline Initial BW $(\mathrm{kg})$ & 801.9 & 810.4 & 17.8 & 0.753 \\
Final BW $(\mathrm{kg})$ & 841.5 & 865.7 & 17.6 & 0.408 \\
ADG $(\mathrm{kg} / \mathrm{d})$ & 0.50 & 0.690 & 0.09 & 0.226 \\
DMI $(\mathrm{kg} / \mathrm{d})$ & 9.1 & 9.0 & 0.41 & 0.688 \\
Gain:feed & 0.054 & 0.077 & 0.02 & 0.189 \\
\hline
\end{tabular}

SSB, starch sugar by-product; SEM, standard error of the mean; BW, body weight; ADG, average daily gain; DMI, dry matter intake.

of the in situ disappearance evaluation, the difference observed between the SSB used in this and the previous study could imply that the nutritional value of SSBs can be increased by changing the starch sugar production process.

Body weight, ADG, DMI, and gain:feed with the SSB supplementation are presented in Table 4 . In the feeding trial, a significant difference in the ADG, DMI, and gain:feed was not observed with an as-fed total mixed ration including $7.0 \%$ (as-fed basis) of SSB when compared to that with the control. In this experiment, the chemical composition of the SSB was similar to that of rice bran; most of the rice bran was replaced by the SSB in the experimental feed. Although a significant difference was not observed between the control and SSB treatment groups, the magnitude of ADG and gain:feed in the SSB treatment group was greater than in the control. Regarding carcass traits, there was no significant difference in most traits except for the dressing percentage (Table 5). It has been reported that a high positive correlation exists between live weight and dressing percentage [27], with a greater correlation in young calves [28]. In contrast, considering cows, it has been reported that the type of diet fed had no association with dressing percentage in Holstein cows [29]. Therefore, the significant difference in dressing percentage between control and SSB treatment groups ( $\mathrm{p}<$ 0.05) can be considered to have been affected by the initial and final BW. Although there was insufficient evidence to suggest that SSB in the diet improves the dressing percentage of Hanwoo steers; it was clear that the SSB is a sufficient substitute for rice bran at 7.0\% (as-fed basis).

In the LM FA profiles, there was no significant difference in each FA (Table 6). Regarding FA content, there was no significant difference between the control and SSB treatment groups. However, there was a significant difference in the ratio of UFA to SFA between the two groups $(\mathrm{p}<0.05)$. Diet and feeding time are more important determinants of meat fat content and FA composition than cattle breed type [30] and most intramuscular fat is synthesized during a late finishing period in ruminants [31]. Although this feeding experiment was of a short term of 80 days, this was sufficient to evaluate the effect of feed on intramuscular fat synthesis. It is well established that there is an increase in monounsaturated fatty acids and a decrease in SFA with increasing time on a grainbased diet [32]. In this study, SFA in LM was greater in the SSB treatment group than in the control $(p<0.05)$, because the non-fiber carbohydrate content of the SSB was lower than that of rice bran. A previous study reported that as carcass quality grade in Hanwoo increased, the ratio of monounsaturated fatty acids to SFA also increased [33]. In this study, although the number of the highest quality grade $\left(1^{++}\right.$grade) steers was more observed with the SSB group than in the control, it needs to be stressed that the lowest quality grade (2 grade) steers were greater in the SSB group than the control. In other words, the possibility that feeding a high level of SSBs could negatively affect the intramuscular fat synthesis of Hanwoo should be considered. In summary, SSBs are a worthwhile by-product to use as an energy and protein source in ruminants. However, it is suggested that feeding is not implemented at more than a $4.0 \%$ of dry basis in Hanwoo.

Table 5. Effects of the dietary starch sugar by-product as a total mixed ration ingredient on carcass traits of Hanwoo steers

\begin{tabular}{|c|c|c|c|c|}
\hline Items & Control & SSB & SEM & p-value \\
\hline Backfat thickness (mm) & 18.43 & 18.53 & 1.29 & 0.963 \\
\hline Dressing (\%) & 61.0 & 63.6 & 0.44 & 0.021 \\
\hline LM area $\left(\mathrm{cm}^{2}\right)$ & 103.68 & 102.11 & 1.53 & 0.507 \\
\hline Carcass weight (kg) & 489.2 & 514.9 & 11.78 & 0.203 \\
\hline Carcass yield grade $^{1)}$ & 2.55 & 2.58 & 0.17 & 0.905 \\
\hline Marbling score & 6.23 & 6.17 & 0.44 & 0.927 \\
\hline Meat color & 4.50 & 4.64 & 0.19 & 0.643 \\
\hline Fat color & 3.00 & 3.00 & 0.05 & 1.000 \\
\hline Texture & 1.00 & 1.36 & 0.08 & 0.080 \\
\hline Maturity & 2.20 & 2.25 & 0.08 & 0.710 \\
\hline Quality grade & 2.17 & 2.08 & 0.19 & 0.778 \\
\hline Frequencies of carcass yield grade (A:B:C, \%) & $7: 29: 64$ & $6: 31: 63$ & - & - \\
\hline Frequencies of carcass quality grade $\left(1^{++}: 1^{+}: 1: 2, \%\right)$ & 21:43:36:0 & $31: 44: 6: 19$ & - & - \\
\hline
\end{tabular}

SSB, starch sugar by-product; SEM, standard error of the mean; LM, Longissimus muscles.

${ }^{1)}$ Carcass traits and grade were evaluated according to guidelines of the Animal Products Grading Service, South Korea (APGS, 1995). 
Table 6. Effects of the dietary starch sugar by-product as a total mixed ration ingredient on longissimus muscle fatty acid composition in Hanwoo steers

\begin{tabular}{|c|c|c|c|c|}
\hline Items & Control & SSB & SEM & p-value \\
\hline C10:0 & 0.08 & 0.08 & 0.02 & 0.683 \\
\hline C12:0 & 0.09 & 0.10 & 0.02 & 0.567 \\
\hline C13:0 & 1.16 & 1.29 & 0.22 & 0.608 \\
\hline C14:0 & 3.17 & 3.73 & 0.51 & 0.284 \\
\hline C15:0 & 0.20 & 0.25 & 0.04 & 0.203 \\
\hline C16:0 & 26.31 & 29.27 & 1.16 & 0.052 \\
\hline C17:0 & 0.45 & 0.49 & 0.08 & 0.585 \\
\hline C18:0 & 9.89 & 10.07 & 0.71 & 0.863 \\
\hline C20:0 & 0.12 & 0.13 & 0.02 & 0.755 \\
\hline $\mathrm{C} 21: 0$ & 0.04 & 0.04 & 0.00 & 0.753 \\
\hline $\mathrm{C} 22: 0$ & 0.56 & 0.64 & 0.22 & 0.686 \\
\hline C23:0 & 0.02 & 0.02 & 0.00 & 0.180 \\
\hline C24:0 & 0.06 & 0.06 & 0.02 & 0.909 \\
\hline C14:1 & 0.95 & 1.25 & 0.25 & 0.341 \\
\hline C16:1 & 4.45 & 4.41 & 1.21 & 0.971 \\
\hline C17:1 & 0.53 & 0.50 & 0.07 & 0.646 \\
\hline C18:1n9-trans & 0.11 & 0.11 & 0.01 & 0.877 \\
\hline C18:1n9-cis & 47.40 & 43.07 & 1.19 & 0.055 \\
\hline C18:2n6-trans & 0.23 & 0.23 & 0.04 & 0.959 \\
\hline C18:2n6-cis & 3.29 & 3.37 & 0.63 & 0.898 \\
\hline C18:3n6 & 0.03 & 0.03 & 0.01 & 0.918 \\
\hline C18:3n3 & 0.08 & 0.08 & 0.01 & 0.377 \\
\hline C20:1 & 0.31 & 0.24 & 0.10 & 0.436 \\
\hline C20:2 & 0.27 & 0.33 & 0.10 & 0.521 \\
\hline C20:3n3 & 0.02 & 0.02 & 0.00 & 0.353 \\
\hline C20:4n6 & 0.02 & 0.02 & 0.00 & 0.490 \\
\hline C20:5n3 & 0.15 & 0.15 & 0.04 & 0.886 \\
\hline SFA & 42.15 & 46.17 & 1.58 & 0.038 \\
\hline UFA & 57.85 & 53.83 & 1.58 & 0.038 \\
\hline MUFA & 53.75 & 49.59 & 0.67 & 0.079 \\
\hline PUFA & 4.09 & 4.24 & 2.07 & 0.897 \\
\hline $\mathrm{U} / \mathrm{S}$ & 1.37 & 1.17 & 0.08 & 0.040 \\
\hline
\end{tabular}

SSB, starch sugar by-product; SEM, standard error of the mean; SFA, saturated fatty acids; UFA, unsaturated fatty acids; MUFA, monounsaturated fatty acids; PUFA, polyunsaturated fatty acids; U/S, UFA/SFA.

\section{IMPLICATIONS}

Starch sugar by-products in the diet can be used for Hanwoo steers without adverse effects on body weight gain and carcass traits. Because starch sugar by-products have adequate crude protein and high gross energy content as a feed ingredient, it is suggested that a total mixed ration containing less than $4.0 \%$ dry matter of starch sugar by-products can be used in Hanwoo steers without a decrease in productivity and carcass traits.

\section{CONFLICT OF INTEREST}

We certify that there is no conflict of interest with any financial organization regarding the material discussed in the manuscript. Youngjun Na is an employee of Antller Inc..

\section{FUNDING}

The authors received no financial support for this article.

\section{ACKNOWLEDGMENTS}

This paper was written as part of Konkuk University's research support program for its faculty on sabbatical leave in 2018.

\section{SUPPLEMENTARY MATERIAL}

Supplementary file is available from: https://doi.org/10.5713/ ab.21.0126

Supplementary Table S1. Physical and chemical characteristics of starch sugar by-product

\section{REFERENCES}

1. Bocquier F, González-García E. Sustainability of ruminant agriculture in the new context: feeding strategies and features of animal adaptability into the necessary holistic approach. Animal 2010;4:1258-73. https://doi.org/10.1017/S175173 1110001023

2. Kato S. Filter cake scraping method and rotary drum filter using the same. United States Patent; 1993. US5262069A.

3. James, Glyn. Sugarcane. Oxford, Oxfordshire, UK: John Wiley \& Sons; Blackwell Publishing Ltd; 2008.

4. Soest PJV. Nutritional ecology of the ruminant. Cornell University Press; 1994.

5. Bailey CB. Silica metabolism and silica urolithiasis in ruminants: a review. Can J Anim Sci 1981;61:219-235. https://doi. org/10.4141/cjas81-031

6. NRC. Nutrient requirements of dairy cattle: seventh revised edition, 2001. Washington, DC, USA: National Academies Press; 2001.

7. Van Soest PJ. Rice straw, the role of silica and treatments to improve quality. Anim Feed Sci Technol 2006;130:137-71. https://doi.org/10.1016/j.anifeedsci.2006.01.023

8. Park SO, Oh GJ, Kim KH. Material flow analysis of animalplant residues generated by the food manufacturing industry. J Korea Soc Waste Manag 2017;34:657-67. https://doi.org/ 10.9786/kswm.2017.34.7.657

9. Gaffney S. Corn refiners association. J Agric Food Inf 2008; 9:94-100.

10. Ørskov ER, McDonald I. The estimation of protein degradability in the rumen from incubation measurements weighted according to rate of passage. J Agric Sci 1979;92:499-503. https://doi.org/10.1017/S0021859600063048

11. ARC. Nutrient requirements of ruminant livestock. Hatfield, Tshwane, South Africa: CAB International, 1994. 
12. Rural Development Administration National Institute of Animal Science. Korean feeding standard for Hanwoo. Suwon, Korea: Rural Development Administration National Institute of Animal Science; 2012.

13. Horwitz W, Latimer GW. Official methods of analysis. 18th ed. Gaithersburg, MD, USA: AOAC International; 2005.

14. Mertens DR, Collaborators. Gravimetric determination of amylase-treated neutral detergent fiber in feeds with fefluxing in feakers or crucibles: Collaborative Study. J AOAC Int 2002; 85:1217-40. https://doi.org/10.1093/jaoac/85.6.1217

15. Van Soest PJ, Robertson JB, Lewis BA. Methods for dietary fiber, neutral detergent fiber, and nonstarch polysaccharides in relation to animal nutrition. J Dairy Sci 1991;74:3583-97. https://doi.org/10.3168/jds.S0022-0302(91)78551-2

16. Möller J, Collaborators. Gravimetric determination of acid detergent fiber and lignin in feed: Interlaboratory Study. J AOAC Int 2009;92:74-90. https://doi.org/10.1093/jaoac/92. 1.74

17. Animal products grading service. Report of business for animal products grading. Sejong, Korea: Korea Institute for Animal Products Quality; 2011.

18. Folch J, Lees M, Stanley GS. A simple method for the isolation and purification of total lipides from animal tissues. J Biol Chem 1957;226:497-509.

19.Lepage G, Roy CC. Direct transesterification of all classes of lipids in a one-step reaction. J Lipid Res 1986;27:114-20. https://doi.org/10.1016/S0022-2275(20)38861-1

20.Garces R, Mancha M. One-step lipid extraction and fatty acid methyl esters preparation from fresh plant tissues. Anal Biochem 1993;211:139-43. https://doi.org/10.1006/abio.1993. 1244

21.SAS institute. Base SAS 9.4 procedures guide 5th ed. Cary, NC, USA: SAS Institute; 2015.

22. Kim S. Feeding value of starch sugar by-product in lactating dairy cows [dissertation]. Seoul, Korea; Konkuk University; 2017.

23. Silva BC, Pacheco MVC, Godoi LA, et al. In situ and in vitro techniques for estimating degradation parameters and digestibility of diets based on maize or sorghum. J Agric Sci 2020; 158:150-8. https://doi.org/10.1017/S0021859620000271

24. Heuzé V, Tran G, Kaushik S. Soybean meal. Feedipedia: a programme by INRA, CIRAD, AFZ and FAO; 2020 [cited 2020 Mar 4]. Available from: https://www.Feedipedia.Org/ Node/674

25. Ehle FR, Murphy MR, Clark JH. In situ particle size reduction and the effect of particle size on degradation of crude protein and dry matter in the rumen of dairy steers. J Dairy Sci 1982; 65:963-71. https://doi.org/10.3168/jds.S0022-0302(82)82297-2

26. Ehle FR. Influence of particle size on determination of fibrous feed components. J Dairy Sci 1984;67:1482-8. https://doi. org/10.3168/jds.S0022-0302(84)81465-4

27. Coyne JM, Evans RD, Berry DP. Dressing percentage and the differential between live weight and carcass weight in cattle are influenced by both genetic and non-genetic factors. J Anim Sci 2019;97:1501-12. https://doi.org/10.1093/jas/skz056

28. Campion B, Keane MG, Kenny DA, Berry DP. Evaluation of estimated genetic merit for carcass weight in beef cattle: Live weights, feed intake, body measurements, skeletal and muscular scores, and carcass characteristics. Livest Sci 2009;126:87-99. https://doi.org/10.1016/j.livsci.2009.06.004

29. Minchin W, Buckley F, Kenny DA, Monahan FJ, Shalloo L, O'Donovan M. Effect of grass silage and concentrate based finishing strategies on cull dairy cow performance, carcass and meat quality characteristics. Meat Sci 2009;81:93-101. https://doi.org/10.1016/j.meatsci.2008.07.001

30. Nuernberg K, Dannenberger D, Nuernberg G, et al. Effect of a grass-based and a concentrate feeding system on meat quality characteristics and fatty acid composition of longissimus muscle in different cattle breeds. Livest Prod Sci 2005;94:13747. https://doi.org/10.1016/j.livprodsci.2004.11.036

31. Lonergan SM, DG Topel, DN Marple. The science of animal growth and meat technology. Amsterdam, Noord-Holland, Netherlands: Academic Press; 2018.

32. Smith SB, Gill CA, Lunt DK, Brooks MA. Regulation of fat and fatty acid composition in beef cattle. Asian-Australas J Anim Sci 2009;22:1225-33. https://doi.org/10.5713/ajas. 2009.r.10

33.Lee YJ, Kim CJ, Kim JH, Park BY, Seong PN, Kang GH. Comparison of fatty acid composition of Hanwoo beef by different quality grades and cuts. Food Sci Anim Res 2010; 30:110-9. 